\title{
CAPITULO 28
}

\section{ATUAÇÃO DE UMA LIGA ACADÊMICA NA CAMPANHA DE VACINAÇÃO NA PANDEMIA DE SARS-COV-2: RELATO DE EXPERIÊNCIA}

DOI 10.4322/978-65-995353-2-1.c28

\author{
Maria Aparecida Melo Morais ${ }^{\mathbf{1}}$, Matheus Gomes Andrade ${ }^{\mathbf{2}}$, Glória Vanessa Araujo \\ Silva Sousa ${ }^{3}$, Anna Beatriz de Almeida Gomes Sousa ${ }^{4}$, Tereza Emanuella Menezes \\ Santos $^{5}$,Mirelly Shatilla Misquita Tavares ${ }^{6}$,Érica Rodrigues Alexandre ${ }^{7}$, Geovana de \\ Abreu Braz ${ }^{8}$, Dilene Fontinele Catunda Melo9, Rosângela Souza Cavalcante ${ }^{10}$ \\ ${ }^{1}$ Faculdade Princesa do Oeste-FPO, (maria.aparecida@alu.fpo.edu.br) \\ ${ }^{2}$ Faculdade Princesa do Oeste-FPO, (matheeusgoms15@gmail.com) \\ ${ }^{3}$ Faculdade Princesa do Oeste-FPO, (gloria.tamboril@gmail.com) \\ ${ }^{4}$ Faculdade Princesa do Oeste-FPO, (annabeatrizs427@ gmail.com) \\ ${ }^{5}$ Faculdade Princesa do Oeste-FPO, (tessemanuella@gmail.com) \\ ${ }^{6}$ Faculdade Princesa do Oeste-FPO, (mirellymesquita2010@hotmail.com) \\ ${ }^{7}$ Faculdade Princesa do Oeste-FPO, (ericarodrigues133@gmail.com) \\ ${ }^{8}$ Faculdade Princesa do Oeste-FPO (geovanabraz45@gmail.com) \\ ${ }^{9}$ Faculdade Princesa do Oeste-FPO, (dilenemelo@ hotmail.com) \\ ${ }^{10}$ Faculdade Princesa do Oeste-FPO, (rosangela.cavalcante@fpo.edu.br)
}

\section{Resumo}

O objetivo do trabalho é relatar experiências vivenciadas nas campanhas de vacinação na pandemia de Sars-coV-2 no município de Crateús-Ceará com o protagonismo de acadêmicos de enfermagem participantes de uma Liga Acadêmica de Saúde da Mulher e da Criança em Enfermagem. Trata-se de um estudo descritivo do tipo Relato de Experiência onde a primeira campanha ocorreu no prédio da faculdade privada na qual os discentes estudam e contemplou pessoas com comorbidades na faixa etária de 35 a 44 anos. Ademais, a vacinação ocorrida em 
12 de julho contemplou o público geral de militares colaboradores do $40^{\circ}$ Batalhão de Infantaria localizado no município de Crateús. Durante a vacinação observou-se e foram seguidos todos os princípios de biossegurança e boas práticas na administração de vacinas a fim de garantir a imunização do público de forma segura. Além disso, foi fundamental a organização da ação, tendo cuidado em seguir as medidas contra a contaminação do Sars-coV2, respeitando o distanciamento social e utilizando-se Equipamentos de Proteção Individual como gorro, máscara cirúrgica ou PPF2, jaleco, e higienização das mãos com álcool em gel entre o atendimento de cada indivíduo. Consoante a aplicação dos imunizantes, alguns acadêmicos estiveram responsáveis pelo correto cadastramento das vacinas aplicadas através do Sistema de Informações do Programa Nacional de Imunizações conforme conferência dos dados como nome completo, número do Cadastro de Pessoa Física e/ou Cadastro Nacional de Saúde, data de nascimento e comprovação de endereço. A experiência vivenciada foi de grande importância para os acadêmicos, pois permitiu a associação teórico-prática e o fortalecimento do tripé ensino-pesquisa-extensão. Além disso, possibilitou uma melhor experiência da vivência relacionada aos diversos setores do cuidado em enfermagem, além de favorecer a participação de discentes em ações onde a teoria e a prática se encontram.

Palavras-chave: Covid-19; Enfermagem; Vacinação.

Área Temática: Ciências da Saúde.

E-mail do autor principal: maria.aparecida@alu.fpo.edu.br

\section{INTRODUÇÃO}

Em 11 de março de 2020, após a população mundial tomar conhecimento dos primeiros casos de uma síndrome respiratória com evolução para Síndrome Respiratória Aguda Grave na cidade de Wuhan, situada na China, a Organização Mundial de Saúde (OMS) decretou estado de pandemia de COVID-19, doença causada pelo novo coronavírus (Sars-CoV-2) (COUTO; BARBIERI; MATOS, 2021). Desde então, muitas medidas preventivas foram necessárias para impedir a infecção pelo vírus e consequente evolução da doença, entre as recomendações, foi proposta a aceleração das vacinas, medidas terapêuticas e diagnósticas (DOMINGUES, 2021). 
Nesse sentido, considerando a imunização por meio de vacinas como um dos métodos mais eficazes no combate a doenças infecciosas, inúmeros esforços foram feitos para que uma vacina eficaz fosse disponibilizada à população (DE FREITAS; DE SOUZA OLIVEIRA et al., 2021).

As vacinas são produtos biológicos que funcionam com base em um conceito de mimetizar a reação imune fisiológica, oferecendo ao sistema imunológico humano o estímulo necessário para que se desenvolva a imunidade sem que o indivíduo tenha que se expor aos riscos da infecção natural. Nesse sentido, cientistas afirmam que a vacina pode evitar a proliferação e os graves danos da COVID-19, protegendo o indivíduo e a coletividade (ANVISA, 2021).

Nesse contexto, após alguns meses do início da Pandemia de COVID-19, e a partir da divulgação pelos laboratórios dos resultados dos ensaios clínicos dos imunobiológicos contra a doença, iniciou-se uma corrida mundial por acordos comerciais a fim de adquirir a tão esperada vacina. Assim, na conjuntura do Brasil, foi compilado um processo de construção de um Plano Nacional de Imunização contra a COVID-19 a fim de definir grupos prioritários para a vacinação baseados em evidências científicas (MACEDO; STRUCHINER; MACIEL, 2021).

Assim, após a comprovação da segurança dos imunizantes, em 17 de janeiro de 2021 a ANVISA autorizou o uso emergencial das vacinas contra a COVID-19 do laboratório Sinovac Life SciencesCo. LTD - vacina adsorvida covid-19 (inativada) - e do laboratório Serum Institute of India Pvt. Ltd [Oxford] - vacina covid-19 (recombinante) (ChAdOx1 nCoV19), o que levou ao início da Campanha Nacional de Vacinação contra a Covid-19 teve início no dia 18 de janeiro de 2021 (BRASIL, 2021).

Desse modo, com a aprovação do uso emergencial das vacinas aprovadas pela ANVISA no Brasil, equipes em todo o país desenvolveram forças tarefas locais para mediar e organizar a administração dos imunobiológicos. Para auxiliar na vacinação, estudantes e profissionais voluntários estão atuando junto às equipes de saúde de cada município nas campanhas de vacinação (BOSSE; MEGIER; PUNGIN et al., 2021).

\section{E - book Tripé do Ensino Superior: Ensino,} Pesquisa e Extensão 
Nesse cenário, foi necessária a organização das campanhas de vacinação em todo território nacional onde se destaca a competência da equipe de enfermagem o manuseio, conservação, preparo, administração, registro e descarte dos resíduos bem como a avaliação e o monitoramento epidemiológico, e privativamente cabe ao enfermeiro a supervisão do trabalho em sala de vacinação (COFEN, 2021).

Diante do exposto, objetiva-se relatar experiências vivenciadas nas campanhas de vacinação na pandemia de Sars-coV-2 no município de Crateús-Ceará com o protagonismo de acadêmicos de enfermagem participantes da Liga Acadêmica de Saúde da Mulher e da Criança em Enfermagem (LASMCE), entidade não governamental que busca o fortalecimento do tripé universitário e a consolidação teórico-prática.

\section{MÉTODO}

Trata-se de um estudo descritivo do tipo Relato de Experiência obtido em campo prático na vacinação contra a Covid-19 ocorrida em 28 de junho e 12 de julho de 2021, vivenciada por oito acadêmicos da Liga Acadêmica de Saúde da Mulher e da Criança em Enfermagem que são discentes do Curso de Bacharelado em Enfermagem de uma faculdade privada, situada no município de Crateús-CE. A pesquisa descritiva é construída a partir da descrição cuidadosa dos fatos e efeitos de uma dada situação, com o objetivo de obter informações sobre questões as quais foram definidas como em investigação (AUGUSTO, 2013).

A primeira campanha em que a liga participou no dia 28 de junho de 2021 ocorreu em sala climatizada no prédio da respectiva faculdade privada na qual os discentes estudam e contemplou pessoas com comorbidades na faixa etária de 35 a 44 anos, participaram neste momento seis ligantes. Ademais, a vacinação ocorrida em 12 de julho de 2021 contemplou o público geral de militares colaboradores do $40^{\circ}$ Batalhão de Infantaria localizado no município 
de Crateús e participaram sete ligantes. Os dois momentos foram supervisionados de forma contínua por duas enfermeiras que são docentes da Instituição, que acompanharam desde a coleta de informações e cadastro dos usuários, coleta de informações do lote até a administração da vacina.

\section{RESULTADOS E DISCUSSÃO}

\subsection{RELATO DE EXPERIÊNCIA}

Na vacinação ocorrida no dia 28 de junho voltada ao público de 35 a 44 anos com comorbidades, os quais tiveram que apresentar atestado médico padrão para COVID-19 no sistema de triagem, foram administradas 200 doses da vacina Janssen imunobiológico de dose única. No dia 12 de julho foram administradas 270 doses da primeira dose da vacina AstraZeneca para o público geral de militares do $40^{\circ}$ Batalhão de Infantaria localizado no município de Crateús. Ambos os dias ocorreram conforme a orientação e supervisão do Setor de Imunização do município, de forma a seguir a faixa etária de avanço da imunização, bem como o atendimento aos grupos prioritários conforme o cadastro prévio no site oficial do governo do Estado.

Nesse contexto, alguns acadêmicos ficaram responsáveis pelo preenchimento dos dados no Sistema de Informação do Programa Nacional de Imunizações (SIPNI), enquanto os demais estavam em sala de vacina seguindo todos os protocolos de biossegurança preconizados para a correta administração de vacinas e realizando as orientações necessárias aos vacinados. Nesse momento, uma situação observada foi as dúvidas acerca dos

\section{E - book Tripé do Ensino Superior: Ensino,} Pesquisa e Extensão 
imunizantes, contraindicações, possíveis efeitos adversos e eficácia, que foram sanadas com a orientação dos ligantes.

Concernente a vacinação, as diluições das vacinas foram feitas respeitando as orientações do fabricante, sendo os frascos multidose, o que permitiu a vacinação de cinco pessoas por frasco. As doses do imunizante da Janssen estiveram armazenadas em temperatura entre $+2^{\circ} \mathrm{C} \mathrm{e}+8^{\circ} \mathrm{C}$, enquanto que as doses da AstraZeneca encontravam-se em temperatura de $39,2^{\circ} \mathrm{F}$, o que equivale a $+4^{\circ} \mathrm{C}$. Assim, as caixas térmicas portáteis estavam devidamente identificadas com termômetro para correta inspeção da temperatura.

Antes da aplicação da dose do imunizante, as pessoas foram orientadas sobre os efeitos mais comuns da vacina e que cada organismo reage de uma forma diferente e por isso, algumas pessoas poderiam não manifestar sintomas e outras poderiam manifestar efeitos adversos. Nesse contexto, na vacinação com as doses da vacina AtraZeneca foi destacado a necessidade de tomar as duas doses necessárias para a completa resposta imunológica e consequente imunização contra a Covid-19.

Quanto ao procedimento técnico para administração da vacina, realizou-se higienização no terço médio do músculo deltóide com algodão seco na vacinação que ocorreu em sala climatizada ofertada pela faculdade, e com algodão embebido em álcool a 70\% na vacinação que ocorreu extramuros. Por tratar-se de uma vacina onde a via de administração é intramuscular, a inserção da agulha foi feita em um ângulo de $90^{\circ}$ para garantir a administração do imunizante no músculo e posterior aspiração do êmbolo para uma maior segurança.

Além disso, foi muito evidente a demonstração de sentimentos de gratidão e felicidade com a tomada da vacina, uma vez que foi um momento muito esperado pela maioria dos vacinados. Logo, foi comum a fotografia do momento para registro e compartilhamento e a utilização de cartazes e blusas como forma de homenagear familiares e amigos vítimas da letalidade da pandemia.

Após a vacinação foram retiradas as dúvidas referentes a reações que a vacina pode causar e reforçado a importância da continuidade dos cuidados contra a contaminação pela Covid-19, visto que a vacina protege apenas contra a evolução para uma forma grave da doença e não garante a imunização imediata do organismo. Nesse contexto, notou-se uma falta 
de conhecimento da população quanto à continuidade das medidas de proteção, o que confere à retirada de dúvidas um caráter de responsabilidade em desmistificar fake news referente à vacinação.

Desse modo, percebeu-se que a participação da liga acadêmica na comunidade foi de extrema magnitude tanto para os ligantes que puderam aprimorar conhecimentos quanto para a população que obteve um serviço de acadêmicos capacitados e compromissados com a biossegurança e as técnicas corretas de administração de vacinas.

Por fim, infere-se que essa vivência permitiu aos acadêmicos vivenciar o protagonismo de estar inseridos na comunidade para realizar ações de prevenção a saúde por meio de uma campanha de vacinação durante uma pandemia. Reconhecendo a importância dessa vivência para a sua formação, tendo a perspectiva de que é um processo fundamental na atuação profissional enfermeiro dentro do contexto da atuação de prevenção da saúde.

\subsection{DISCUSSÃO}

As vacinas surgiram como uma forma de minimizar os impactos causados por epidemias avassaladoras. Elas seriam uma medida de controle de doenças de grande impacto nas condições de vida de uma população, funcionando como forma primária de prevenção e erradicação de diferentes patologias (LIMA; DOS SANTOS PINTO, 2017).

Nesse contexto, no que se refere à vacinação contra a Covid-19, o rápido desenvolvimento de vacinas representa um importante avanço da ciência e da saúde pública e alimenta a esperança de superação da pandemia (DE SOUZA; BUSS, 2021). Assim, o sucesso da vacinação depende da adesão da população às campanhas.

É fato que ao se atingir elevadas coberturas vacinais, além de reduzir casos de doença na população-alvo estabelecida para a vacinação, contribui para a diminuição da circulação de agentes infecciosos nas comunidades, impactando positivamente na saúde daqueles que não serão vacinados, uma vez que passam a estar protegidos indiretamente (DOMINGUES, 2021).

\section{E - book Tripé do Ensino Superior: Ensino,} Pesquisa e Extensão 
Nesse sentido, as campanhas de vacinação contra a Covid-19 se inserem no cenário pandêmico como estratégia de redução da transmissão da doença e consequente proteção da sociedade em geral.

A imunização, por meio da vacinação dos indivíduos de uma sociedade, é entendida como uma atividade da atenção primária à saúde, devendo ser oferecida de forma universal e equânime, obedecendo aos princípios do SUS (PEDREIRA, 2021). Portanto, a experiência relatada apresenta um grande caráter de relevância, uma vez que a forma de administração das vacinas e o entendimento da importância da humanização na realização do procedimento motivam a maior adesão da população à campanha.

\section{CONCLUSÃO}

A experiência vivenciada foi de grande importância para os acadêmicos ligantes, sobretudo por ter sido em meio a uma pandemia, o que auxiliou no alcance dos índices almejados de imunização daquele município, além de permitir a associação teórico-prática e o fortalecimento do tripé universitário ensino-pesquisa-extensão o qual a liga objetiva para seu crescimento e desenvolvimento. Além disso, possibilitou uma melhor experiência da vivência relacionada aos diversos setores do cuidado em enfermagem e favoreceu a participação de discentes em ações onde a teoria e as práticas se encontram.

Como supracitado, ao colocar em prática a teoria antes aprendida, facilita a melhor compreensão e fixação do conteúdo, como as teorias e técnicas para vacinação que foram postas em prática durante a ação. Ressaltando sempre a importância da biossegurança e das boas práticas na administração de vacinas para garantir a segurança de ambas as partes.

Assim, a extensão da Liga Acadêmica de Saúde da Mulher e da Criança torna-se uma experiência que proporciona aos acadêmicos de enfermagem a participarem das atividades na comunidade fortalecendo a relação interpessoal do profissional com os usuários, resultando numa atenção integral resolutiva pela transformação e qualificação do SUS. 


\section{REFERÊNCIAS}

AGÊNCIA NACIONAL DE VIGILÂNCIA SANITÁRIA (ANVISA). Relatório-Bases técnicas para decisão do uso emergencial, em caráter experimental de vacinas contra a covid19. S.I: S.I., 2021.

AUGUSTO, C. A. et al. Pesquisa Qualitativa: rigor metodológico no tratamento de teoria dos custos de transação em artigos apresentados nos congressos da Sober (2007-2011). RESR, Piracicaba-SP; Vol. 51, N 4, p.745-764, 2013.

BOSSE, Bruna Rodrigues et al. CAMPANHA DE VACINAÇÃO COVID-19 EM SANTA MARIA, RIO GRANDE DO SUL: RELATO DE EXPERIÊNCIA. In: Congresso Internacional em Saúde. 2021.

CONSELHO FEDERAL DE ENFERMAGEM (COFEN). Medidas de prevenção e controle para profissionais na vacinação contra covid-19. S.I: S.I., 2021.

COUTO, Marcia Thereza; BARBIERI, Carolina Luisa Alves; MATOS, Camila Carvalho de Souza Amorim. Considerações sobre o impacto da covid-19 na relação indivíduo-sociedade: da hesitação vacinal ao clamor por uma vacina. Saúde e Sociedade, v. 30, 2021.

DE FREITAS, Maria Bethânia Alves; DE SOUZA OLIVEIRA, Mikael; MACIEL, Ivana Maria Esteves. Adesão à vacina contra a Covid-19 pela comunidade acadêmica do UNIFUNEC. UNIFUNEC CIÊNCIAS DA SAÚDE E BIOLÓGICAS, v. 4, n. 7, p. 1-14, 2021.

DE SOUZA, Luis Eugenio Portela Fernandes; BUSS, Paulo Marchiori. Desafios globais para o acesso equitativo à vacinação contra a COVID-19. Cad. Saúde Pública, v. 37, n. 9, p. e00056521, 2021.

DOMINGUES, Carla Magda Allan Santos. Desafios para a realização da campanha de vacinação contra a COVID-19 no Brasil. 2021.

LIMA, Adeânio Almeida; DOS SANTOS PINTO, Edenise. O contexto histórico da implantação do Programa Nacional de Imunização (PNI) e sua importância para o Sistema Único de Saúde (SUS). Scire Salutis, v. 7, n. 1, p. 53-62, 2017.

MACEDO, Laylla Ribeiro; STRUCHINER, Claudio Jose; MACIEL, Ethel Leonor Noia. Contexto de elaboração do Plano de Imunização contra COVID-19 no Brasil. Ciência \& Saúde Coletiva, v. 26, p. 2859-2862, 2021.

Ministério da Saúde (MS). PLANO NACIONAL DE OPERACIONALIZAÇÃO DA VACINAÇÃO CONTRA A COVID-19. Brasília-DF: S.I., 2021.

PEDREIRA, Nábia Pereira et al. Vivência do acadêmico de enfermagem frente à campanha de vacinação ao combate a pandemia da COVID-19. Revista Eletrônica Acervo Saúde, v. 13, n. 5, p. e7326-e7326, 2021.

E - book Tripé do Ensino Superior: Ensino, Pesquisa e Extensão 